Review

\title{
Electrodeposition of Ni-Co Film: A Review
}

\author{
Inam M.A. Omar ${ }^{1,2}$, Khadijah M. Emran ${ }^{3, *}$, Madzlan Aziz ${ }^{4}$ \\ ${ }^{1}$ Chemistry Department, College of Science, Taibah University, AlMaddinah Al Mounwara, SAUDI \\ ARABIA. \\ ${ }^{2}$ Department of Chemistry, Faculty of Science, Universiti Teknologi Malaysia, 81310 Johor Bahru, \\ Johor, MALAYSIA. \\ ${ }^{3}$ Chemistry Department, College of Science, Taibah University, AlMaddinah Al Mounwara, SAUDI \\ ARABIA \\ ${ }^{4}$ Department of Chemistry, Faculty of Science, Universiti Teknologi Malaysia, 81310 Johor Bahru, \\ Johor, MALAYSIA. \\ *E-mail: kabdalsamad@taibahu.edu.sa
}

doi: 10.20964/2021.01.16

Received: 25 September 2020 / Accepted: 3 November 2020 / Published: 30 November 2020

\begin{abstract}
Nickel (Ni), cobalt (Co) and their alloy have been extensively employed in engineering due to their magnetic, chemical, mechanical, physical and electrocatalytic characteristics, which grant resistance against corrosion and heat. Electrodeposition is considered to be a significant and environmentally friendly technique for producing $\mathrm{Ni}$, Co and their alloy coatings due to its promising properties. The current research provides a brief review of the latest studies of different types of $\mathrm{Ni}, \mathrm{Co}$, and Ni-Co alloy electrodeposition from different aqueous baths. This article reviews the effects of various organic additives in $\mathrm{Ni}, \mathrm{Co}$ and their alloy electrodeposition processes. Due to the special functions of organic additives, they are widely used during electrodeposition. The additives usually affect the growth and crystal building of deposits through their adsorption on the cathode surface. The widened electrochemical window, superior thermal stability, negligible or low vapor pressure and the environmentally friendly characteristics of ionic liquids (ILs) permit them to be promising replacements for traditional, toxic and volatile organic solvents.
\end{abstract}

Keywords: Electrodeposition, Ni-Co alloy, Ionic liquids, additives, Cathodic current efficiency, Voltametric measurements.

\section{$\underline{\text { FULL TEXT }}$}

(C) 2021 The Authors. Published by ESG (www.electrochemsci.org). This article is an open access article distributed under the terms and conditions of the Creative Commons Attribution license (http://creativecommons.org/licenses/by/4.0/). 